(C) 2016 IEEE. Personal use of this material is permitted. Permission from IEEE must be obtained for all other uses, in any current or future media, including reprinting/republishing this material for advertising or promotional purposes, creating new collective works, for resale or redistribution to servers or lists, or reuse of any copyrighted component of this work in other works. 


\title{
Benchmarking of Real-Time LTE Network in Dynamic Environment
}

\author{
Ramprasad Subramanian, Dr. Kumbesan Sandrasegaran, Dr. Xiaoying Kong \\ Centre for Real Time Information Networks \\ School of Computing and Communication \\ Faculty of Engineering and Information Technology University of Technology Sydney \\ Sydney, Australia
}

\begin{abstract}
LTE/LTE-A is high speed wireless communication technology which got evolved from 2G/3G. LTE provides very high throughput in uplink and downlink and hence it is attracting more and more subscribers every day. This paper analyzes the performance of real time LTE network of two different LTE service providers through drive test. Test cases were performed under dynamic environment where the test user is dynamic or the environment around the test user is dynamic (travelling in train or car). The performance comparison of different Key Performance Indicators (KPI) such as Reference Signal Received Power (RSRP), Reference Signal Received Quality (RSRQ), Reference Signal Strength Indicator (RSSI) and throughput (uplink - UL and downlink - DL) are made between the two LTE service providers. The performance tests were performed using Nemo tool in a real-time LTE network. Average values were obtained for different KPIs to study the performance of the LTE network.
\end{abstract}

Keywords-LTE; RSRP; RSRQ; RSSI; throughput; benchmark; real-time; Nemo; drive test.

\section{INTRODUCTION}

LTE is the successor technology of third generation telecommunication standard which is popularly called as $3 \mathrm{G}$. LTE provides the peak download speed of $100 \mathrm{Mbps}$ in downlink and $50 \mathrm{Mbps}$ in the upload. Release 10 of LTE is supports IMT Advanced, which provide $300 \mathrm{Mbps}$ in the download but still falls short of IMT - Advanced standards which is $1 \mathrm{Gbps}$ in the peak download and $500 \mathrm{Mbps}$ in the uplink. Air interface in LTE network utilizes two types of duplexing namely LTE- FDD (Frequency division duplex) and LTE-TDD (Time division duplex) to achieve high data rates associated with the $4 \mathrm{G}$ technology. At this point LTE-FDD is widely used technology. The reason credited to this being, LTE-FDD provides greater compatibility with the existing and prospective spectrum assignments. But, the implementation of TDD is gradually picking up. The physical channels in LTE can be classified as physical downlink shared channel (PDSCH) that transports user data and modulated using QPSK, 16-QAM or 64-QAM. The physical broadcast channel $(\mathrm{PBCH})$ sends cells specific system identification and control parameters using QPSK every 40 millisecond. The Physical Downlink Control Channel (PDCCH) provides the resources to the UE and the reference signal (RS) is used for channel estimation. In the uplink, the Physical Uplink Control Channel
(PUCCH) handles the control information and responses of the UE. The physical uplink shared channel (PUSCH) is similar to PDSCH. However, it handles the uplink using QPSK, 16-QAM or 64-QAM. This capacity of the LTE/LTEA attracts new subscribers and as a result of this operators are expanding the network at a rapid rate to increase the capacity and coverage to many areas that are still uncovered. LTE is based on the SC-FDMA in uplink and OFDMA in the downlink. Hence, an attempt has been made to benchmark the network coverage of this technology between two leading LTE/LTE-A service providers. Hereafter we call the service providers as Operator-A and Operator-B.

Benchmarking testing is an act of performing same tests between the service providers in order to assess the relative performance of the service providers. In these tests, the network performance of Operator A and B are compared. Both the service providers have an ambitious network roll out plan for future. Operator A for instance, planning to shut down the $2 \mathrm{G}$ network operations by 2016 and they are planning to allocate the spectrum used by $2 \mathrm{G}$ to LTE. They have also extended the $700 \mathrm{MHz}$ LTE trials in two major cities. Apart from this, to boost the data speed Operator A has introduced carrier aggregation using three bands to deliver data rate up to $450 \mathrm{Mbps}$. Furthermore, Operator-A is using nationwide fibre service to reach out to various communities across the country to expand the LTE/LTE-A coverage.

On the other hand, Operator-B is aiming to cover $98.5 \%$ of the population with the LTE by end of 2016 where the initial the service was started by Operator-B in the year 2013. Subsequent to the launch, the network was rolled out across various metropolitans in the country. The roll out was planned in such a way that new mobile sites were installed and some sites were upgraded to have combined $4 \mathrm{G}$ technologies of LTE-TDD (2300MHz) and LTE-FDD (1800 MHz). Operator $\mathrm{B}$ also has plans to utilize $700 \mathrm{MHz}$ and $2600 \mathrm{MHz}$ for $4 \mathrm{G}$.

The purpose of this paper is to analyse the real time LTE network under dynamic condition by explaining the key power measurements reported by LTE enabled cell phone. The effect of mobility on a LTE user is studied by monitoring KPIs such as UL/DL through, RSSI, RSRP, and RSRQ. The results of two real-time networks are compared.

The rest of the paper is organized as follows: Section II provides important definition about KPIs monitoring in this 
paper; Section II explains the benchmarking testing methodology; Section IV presents the test results, and Section $\mathrm{V}$ gives the conclusion of this testing.

\section{SIGNAL POWER MEASUREMENT INDICATORS IN LTE NETWORK}

The KPIs such as RSRP, RSRQ and RSSI provides information regarding quality of the wireless channel in LTE network. These measurements are conducted over Resource Elements (RE) that contains Reference Symbols (RS). The fourth and sixth REs contain RS, and RSs are transmitted in the first and fourth OFDM symbol of each RB. Each OFDM consists of REs in fourth and sixth [1]. RSRP is a cell specific metric denoting received signal strength that is used by LTE enabled User Equipments (UE) for cell re-selection and handover. The definitions of KPIs are given below.

RSSI can be defined as the total power received in a single $\mathrm{RE}$ in a RB [2][3]. RE which is a smallest data unit in LTE standard represents $15 \mathrm{KHz}$ in frequency domain and 1 OFDM symbol in time domain. Each RB constitutes $12 \mathrm{RE}$ which corresponds to $(12 * 15) 180 \mathrm{KHz}$ in frequency domain and $0.5 \mathrm{msec}$ in time domain. It includes all the power from neighbor, serving cells and noise. Its units are defined in $\mathrm{dBm}$. RSRP can be defined as power measured in a single RE. It is represented as the power of single RE which contains reference signal. RSRP does not include noise or interference from serving or neighboring cells. Its units are given as $\mathrm{dBm}$. The value of RSRP is given as Energy Per Resource Element (EPRE) in every eNB. The unit of EPRE is defined as $\mathrm{dBm} / 15$ $\mathrm{KHz}$, which is defined as power per $15 \mathrm{KHz}$ or per RE. RSRQ can be defined as the quality of power received in RE that contains RS. It is an important KPI to assess the quality of the received signal. It is defined as follows;

$$
R S R Q=N \frac{R S R P}{R S S I}
$$

As seen in Equation 1, RSRQ is calculated using RSRP and RSSI. This is used as the reference signal by the LTE network to make hand-off decision. $\mathrm{N}$ is the number of $\mathrm{RBs}$ and its value changes depending on the scheduling to the specific user. CQI is in the uplink direction transmitted by UE to the network. The UE transmits the channel quality as the feedback to the eNB. The CQI report by UE to the eNB is a vital information used by eNB to make critical decisions regarding scheduling. The better the wireless channel, the higher will be the CQI from a UE. This is used to decide on modulation formats, packet types, pre-coding matrix types which affects the throughput delivered to a particular user [4][5].

\section{TEST METHODOLOGY}

Benchmarking is a relative performance evaluation between various service providers. The main objective of the testing is to assess the performance of the various parameters of the LTE network with similar test cases and tools. The objective of our testing is:

- To analyse the $4 \mathrm{G}$ network measurement in different scenarios.

- To compare the network performance between Operator A and Operator B in a select locations in a huge metropolitan city.
LTE capable UE is used in real LTE network for all the test cases. The entire test cases where performed in $10 \mathrm{MHz}$ LTE network. The tests were carried out in sub-urban environment. Testing consist of different scenarios such as walk test in urban city center, drive testing in car, while travelling in train and inside the international airport. The LTE UE is connected to laptop and logs were collected using Nemo software. The speed of the test UE was not controlled. The testing was designed in such a way that UE should travel without control so that testing could be performed closed to the real world scenario as much as possible.

Nemo test tool - The testing is carried out by using Nemo hand held drive test tool. Nemo supports various technologies like GSM, CDMA, EVDO, WCDMA, HSPA, HSPA+, LTE and Wi-Fi. It also supports measuring and monitoring QoS/QoE of various applications. The script to monitoring and recording various QoS parameters for voice call, HTTP accessing can be modified as per the test case design. The interface options used in the testing:

- Carrier RSSI - values range from -140 to -10

- Serving SNR - Displays the SNR (signal to noise ratio) for the serving channel in $\mathrm{db}$.

- Serving RSRQ - Displays the reference signal received quality for the serving channel in $\mathrm{db}$. Range -30 to 0 .

- Serving RSRP - Displays the reference signal received power for the serving channel in $\mathrm{dBm}$. Range -140 to 0 .

As previously stated, Nemo Handy also allows the user to monitor and record measurements in different situations by creating scripts. Scripts can automate various features that include: Voice call, Text message, video streaming, HTTP accessing, etc. The files created from the Nemo handy are analysed using the Nemo outdoor analysis tool that can support over 280 terminals.

Test scenarios - In order to verify the LTE network performance, two service providers were selected: Operator A and Operator B. The below tests were performed as close as possible over the same routes and areas to provide an accurate comparison between Operator A and Operator B performance. In the real-time testing, our scenarios were considered for testing:

- Walking test: Data was collected by walking around city center.

- Train test: Data was collected whilst travelling in a train.

- Driving test: Data was collected by driving in a car.

- Indoor test: In order to test the performance inside the International Airport.

In our testing, the same script was used to test the various transmissions in different LTE environment.

The script includes:

- FTP transfer

- HTML Browsing

- Send SMS 


\section{BENCHMARK TESTING AND RESULTS}

\section{A. Experiment 1 -Walk test:}

This test was conducted while walking around the city center in the heart city. The below Tablel and Table 2 provide KPI measurements of RSRP, RSRQ, RSSI and uplink/ downlink (with minimum, maximum and average) of both Operator A and Operator B respectively.

TABLE 1. OPERATOR A KPI MEASUREMENT - WALK TEST

\begin{tabular}{|l|l|l|l|}
\hline $\begin{array}{l}\text { Measurement } \\
\text { parameter }\end{array}$ & Min value & Max value & Average \\
\hline RSRP (dBm) & -109.3 & -68.1 & 73.34 \\
\hline RSRQ (dBm) & -22.6 & -1.4 & -6.7 \\
\hline RSSI & -82.90 & -37.36 & -58.6 \\
\hline $\begin{array}{l}\text { Throughput } \\
\text { in DL (bits/s) }\end{array}$ & 0 & 320000 & \\
\hline $\begin{array}{l}\text { Throughput } \\
\text { in UL (bits/s) }\end{array}$ & 0 & 1064000 & \\
\hline
\end{tabular}

TABLE. 2. OPERATOR B KPI MEASUREMENT - WALK TEST

\begin{tabular}{|l|l|l|l|}
\hline $\begin{array}{l}\text { Measurement } \\
\text { parameter }\end{array}$ & Min value & $\begin{array}{l}\text { Max } \\
\text { value }\end{array}$ & Average \\
\hline RSRP (dBm) & -117.8 & -64.2 & -91.0 \\
\hline RSRQ (dBm) & -23.3 & -0.1 & -12.2 \\
\hline RSSI & -90.2 & -33.6 & -70.2 \\
\hline $\begin{array}{l}\text { Throughput } \\
\text { in DL (bits/s) }\end{array}$ & 0 & 280000 & \\
\hline $\begin{array}{l}\text { Throughput } \\
\text { in UL (bits/s) }\end{array}$ & 0 & 1032000 & \\
\hline
\end{tabular}

Performance of Operator A around city center is better than Operator B in terms of quality and received signal strength. The RSSI indicates effective signal to noise ratio, the average RSSI for Operator B is high compared to Operator A which indicates that quality of received signal in Operator $A$ is better than Operator B. On the other hand, high RSRQ for Operator B indicates frequent hand-off while walking in around the city center. During the test it was observed that Operator A is using two ports (port 0 and port 1) in antenna to support MIMO in eNB. The benefit of using MIMO was evident in the KPIs. Figure 1 and Figure 2 indicates the walk test for Operator A and Operator B. Table 1 and Table 2 indicate the KPI measurement for the test.
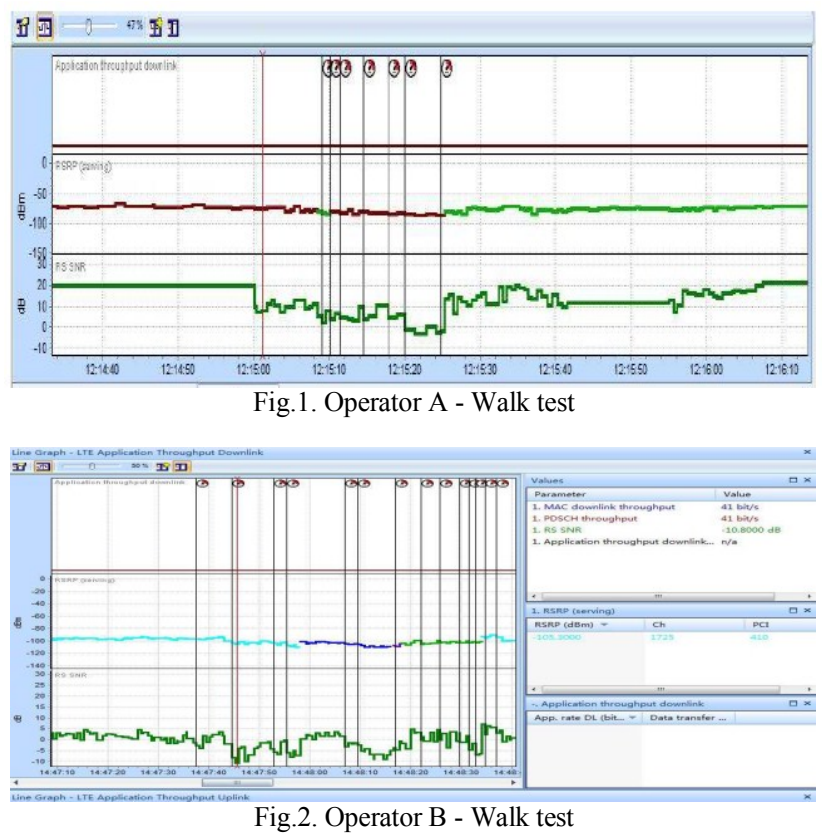

B. Experiment 2 - Train test:

This test conducted while travelling in the train from Station A to Station B. In the figures, it shows that for most of the time, the serving RSRP and RSRQ of Operator A maintains high level of network quality and coverage. However, the serving signal power reduces to -115 from -90 $\mathrm{dBm}$ inside a tunnel near to the station. On the other hand, the network coverage for Operator B varies between $-74.4 \mathrm{dBm}$ to $-131.6 \mathrm{dBm}$. The variation in RSRQ is higher than Operator A which resulted in more handoff.

TABLE 3. OPERATOR A KPI MEASUREMENT - TRAIN TEST

\begin{tabular}{|l|l|l|l|}
\hline $\begin{array}{l}\text { Measurement } \\
\text { parameter }\end{array}$ & Min value & $\begin{array}{l}\text { Max } \\
\text { value }\end{array}$ & Average \\
\hline RSRP (dBm) & -109.1 & -65.2 & -95.4 \\
\hline RSRQ (dBm) & -14.3 & -0.3 & -6.3 \\
\hline RSSI & -82.4 & -41.1 & -59.8 \\
\hline $\begin{array}{l}\text { Throughput } \\
\text { in DL (bits/s) }\end{array}$ & 0 & 280000 & \\
\hline $\begin{array}{l}\text { Throughput } \\
\text { in UL (bits/s) }\end{array}$ & 0 & 142857 & \\
\hline
\end{tabular}

TABLE.4. OPERATOR B KPI MEASUREMENT - TRAIN TEST

\begin{tabular}{|l|l|l|l|}
\hline $\begin{array}{l}\text { Measurement } \\
\text { parameter }\end{array}$ & Min value & $\begin{array}{l}\text { Max } \\
\text { value }\end{array}$ & Average \\
\hline RSRP (dBm) & -131.6 & -74.4 & -96.5 \\
\hline RSRQ (dBm) & -25.2 & -4.7 & -14.9 \\
\hline
\end{tabular}




\begin{tabular}{|l|l|l|l|}
\hline RSSI & -94.3 & -43.4 & -70.2 \\
\hline $\begin{array}{l}\text { Throughput } \\
\text { in DL (bits/s) }\end{array}$ & 0 & 280000 & \\
\hline $\begin{array}{l}\text { Throughput } \\
\text { in UL (bits/s) }\end{array}$ & 0 & 1032000 & \\
\hline
\end{tabular}

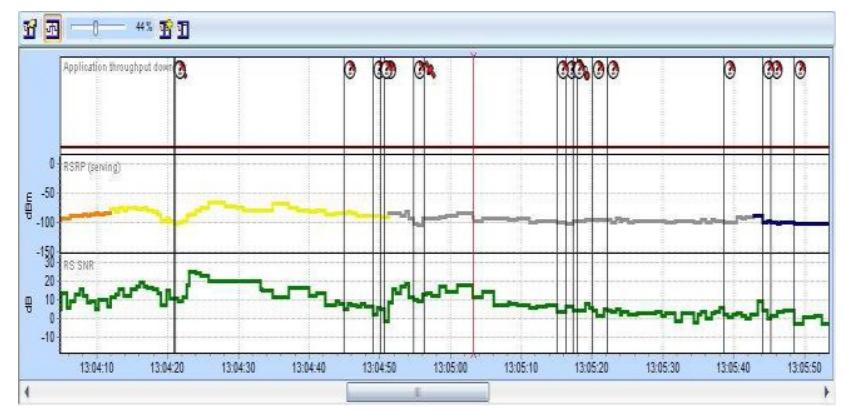

Fig.3. Operator A - Train test

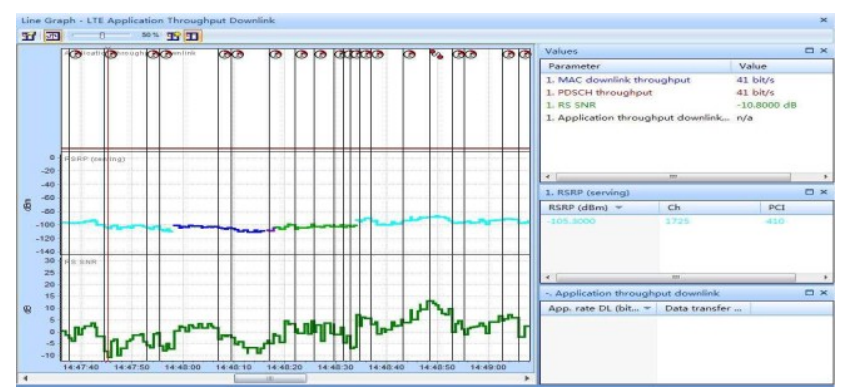

Fig.4. Operator B - Train test

Figure 3 and Figure 4 indicates the train test for Operator A and Operator B. Table 3 and Table 4 indicate the KPI measurement for the test.

\section{Experiment 3 -Drive test in a car inside the city:}

This test was done while driving with a car inside the city. The red patches in the Figure 5 for Operator A indicate that serving power was unstable and choppy in certain locations. But on the whole throughout this test the quality was high to maintain high performance in terms of throughout. For Operator $\mathrm{B}$, the received signal strength was better than Operator A and the quality of the link was similar to Operator A. But RSRP for Operator A is better than Operator B which indicates that Operator-A have less noise in the signal than Operator B from neighbouring cells. The same is reflected in RSRQ as well. This indicates that to boost the quality of the received signal appropriate cell planning is the right strategy than increasing the number of eNBs.

TABLE.5. OPERATOR-B KPI MEASUREMENT - DRIVE TEST CAR

\begin{tabular}{|l|l|l|l|}
\hline $\begin{array}{l}\text { Measurement } \\
\text { parameter }\end{array}$ & Min value & $\begin{array}{l}\text { Max } \\
\text { value }\end{array}$ & Average \\
\hline RSRP (dBm) & -110.9 & -75.1 & -82.0 \\
\hline
\end{tabular}

\begin{tabular}{|l|l|l|l|}
\hline RSRQ (dBm) & -13.8 & -0.3 & -6.5 \\
\hline RSSI & -94.4 & -30.4 & -69.3 \\
\hline $\begin{array}{l}\text { Throughput } \\
\text { in DL (bits/s) }\end{array}$ & 0 & 248000 & \\
\hline $\begin{array}{l}\text { Throughput } \\
\text { in UL (bits/s) }\end{array}$ & 0 & 299200 & \\
\hline
\end{tabular}

TABLE.6. OPERATOR-B KPI MEASUREMENT -DRIVE TEST CAR

\begin{tabular}{|l|l|l|l|}
\hline $\begin{array}{c}\text { Measurement } \\
\text { parameter }\end{array}$ & Min value & $\begin{array}{l}\text { Max } \\
\text { value }\end{array}$ & Average \\
\hline RSRP (dBm) & -131.6 & -74.4 & -96.5 \\
\hline RSRQ (dBm) & -25.2 & -4.7 & -14.9 \\
\hline RSSI & -94.3 & -43.4 & -70.2 \\
\hline $\begin{array}{l}\text { Throughput } \\
\text { in DL (bits/s) }\end{array}$ & 0 & 280000 & \\
\hline $\begin{array}{l}\text { Throughput } \\
\text { in UL (bits/s) }\end{array}$ & 0 & 1032000 & \\
\hline
\end{tabular}

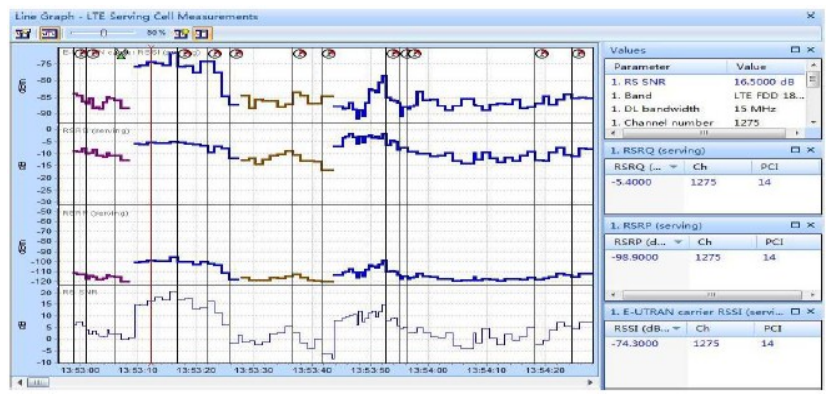

Fig.5. Operator A - Drive test in car

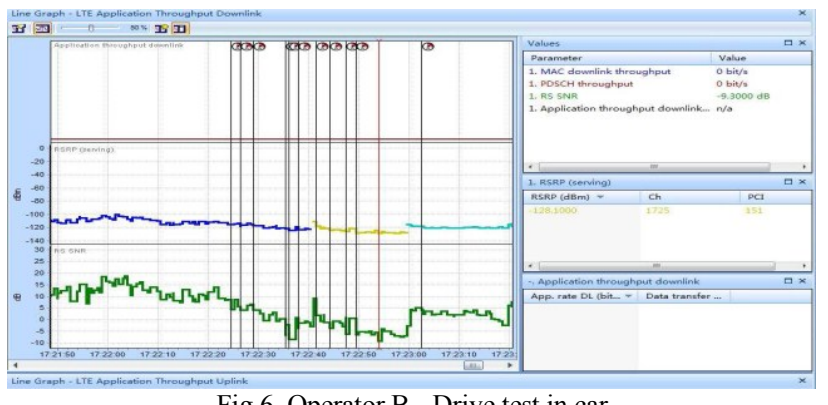

Fig.6. Operator B - Drive test in car

Figure 5 and Figure 6 indicates the train test for Operator A and Operator B. Table 1 and Table 2 indicate the KPI measurement for the test.

\section{Experiement 4 - Inside the Internation airport}

This test conducted inside the international airport. The user remained stationary during the test. Since, it is an airport there was constant movement of people and trolleys around the 
test user. Apart from this airport is a closed environment with metal and glass structures which may affect the quality of the received signal. The impact of structures and reflections are evident in Table 7 for Operator A. The average RSSI is high compared to RSRP which indicates that noise level in the signal high due to reflections and absorptions. Similar behavior is observed in Operator B (Table 8). Hence, appropriate planning is required to negate the impacts of reflections and absorptions emanating due to the building structures.

TABLE.7. OPERATOR-B KPI MEASUREMENT -DRIVE TEST CAR

\begin{tabular}{|l|l|l|l|}
\hline $\begin{array}{c}\text { Measurement } \\
\text { parameter }\end{array}$ & Min value & $\begin{array}{l}\text { Max } \\
\text { value }\end{array}$ & Average \\
\hline RSRP (dBm) & -100 & -112 & -105.6 \\
\hline RSRQ (dBm) & -5.4 & 16.3 & -7.9 \\
\hline RSSI & -71.6 & -93.9 & -85.3 \\
\hline $\begin{array}{l}\text { Throughput } \\
\text { in DL (bits/s) }\end{array}$ & 0 & 248000 & \\
\hline $\begin{array}{l}\text { Throughput } \\
\text { in UL (bits/s) }\end{array}$ & 0 & 112000 & \\
\hline
\end{tabular}

TABLE.8. OPERATOR-B KPI MEASUREMENT -DRIVE TEST CAR

\begin{tabular}{|l|l|l|l|}
\hline $\begin{array}{l}\text { Measurement } \\
\text { parameter }\end{array}$ & Min value & $\begin{array}{l}\text { Max } \\
\text { value }\end{array}$ & Average \\
\hline RSRP (dBm) & -122.4 & -111.2 & 116.4 \\
\hline RSRQ (dBm) & -28.2 & -7.1 & -17.65 \\
\hline RSSI & -94.7 & -80.9 & -86.2 \\
\hline $\begin{array}{l}\text { Throughput } \\
\text { in DL (bits/s) }\end{array}$ & 0 & 232000 & \\
\hline $\begin{array}{l}\text { Throughput } \\
\text { in UL (bits/s) }\end{array}$ & 0 & 218000 & \\
\hline
\end{tabular}

Figure 7 and Figure 8 indicates the testing of Operator A and Operator B inside the international airport.

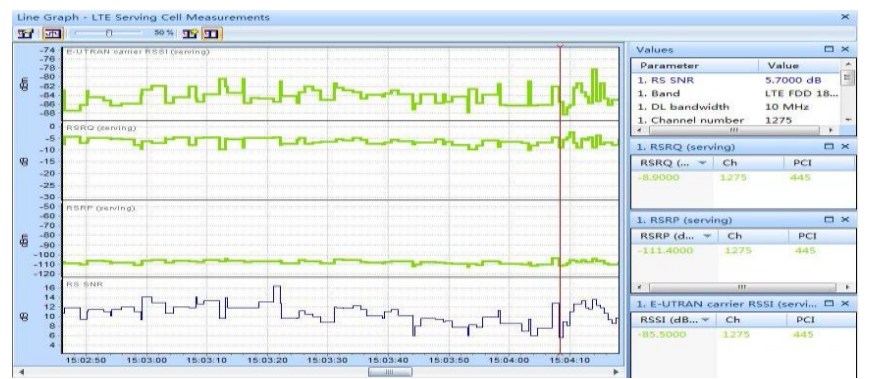

Fig.7. Operator A - Inside the international airport

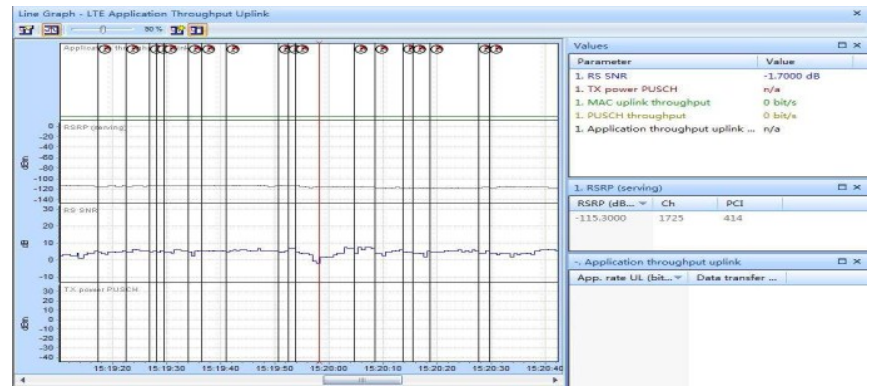

Fig.7. Operator B - Inside the international airport

\section{CONCLUSION}

At the end of the benchmarking test, performed in various locations and in various modes such as walking around the city center, travelling in train, driving in the car and in indoor environments, the main similarity between the Operator A and Operator B was that both were using 1800 frequency band and both were using FDD-LTE. According to the values obtained during the drive test, we can conclude that the performance of Operator A in all the four identified test scenarios was better than Operator B (Table 9). Operator A performance was much stable even in high speed moving condition. However, the received signal strength in of Operator A can be enhanced inside the indoor (airport) condition. For Operator B, the performance of the LTE network was stable in the CBD area and in the train. But the performance got degraded while driving in the car inside the urban condition. Furthermore, the Operator A and Operator B did not have enough coverage inside the tunnels and in the underground passage. The network performance can be enhanced if these concerns can be addressed by the service providers in immediate future.

TABLE.9. KPI SUMMARY BETWEEN THE OPERATOR

\begin{tabular}{|l|l|l|l|l|}
\hline $\begin{array}{l}\text { Service } \\
\text { provides }\end{array}$ & CBD & Train & Driving & Indoor \\
\hline \multicolumn{5}{|c|}{ RSRP } \\
\hline $\begin{array}{l}\text { Operator } \\
\text { A }\end{array}$ & -73.34 & -95.4 & -82.0 & -105.0 \\
\hline $\begin{array}{l}\text { Operator } \\
\text { B }\end{array}$ & -91.0 & -96.5 & -103.1 & -116.4 \\
\hline \multicolumn{5}{|c|}{ RSRQ } \\
\hline $\begin{array}{l}\text { Operator } \\
\text { A }\end{array}$ & -6.7 & -6.3 & -6.5 & -7.9 \\
\hline $\begin{array}{l}\text { Operator } \\
\text { B }\end{array}$ & -12.2 & -14.9 & -15.1 & -17.65 \\
\hline \multicolumn{5}{|c|}{ RSSI } \\
\hline $\begin{array}{l}\text { Operator } \\
\text { A }\end{array}$ & -58.6 & -59.8 & -69.3 & -85.3 \\
\hline $\begin{array}{l}\text { Operator } \\
\text { B }\end{array}$ & -70.2 & -75.3 & -77.3 & -86.2 \\
\hline
\end{tabular}




\section{REFERENCE}

[1] 3GPP TS 36.211, Evolved Universal Terrestrial Radio Access (EUTRA); Physical Channels and Modulations.

[2] 3GPP TS 36.214, Evolved Universal Terrestrial Radio Access (EUTRA); Physical layer - Measurements.

[3] 3GPP TS 25.215, Physical layer Measurements (FDD).

[4] 3GPP TS 36.133, Evolved Universal Terrestrial Radio Access (EUTRA): Requirements for support of radio resource management.

[5] 3GPP TS 36.331, Evolved Universal Terrestrial Radio Access (EUTRA); Radio Resource Control (RRC); Protocol specification. 